\title{
Incidentally detection of non-palpable testicular nodules at scrotal ultrasound: What is new?
}

\author{
Massimo Valentino ${ }^{1}$, Michele Bertolotto ${ }^{2}$, Pasquale Martino ${ }^{3}$, Libero Barozzi ${ }^{4}$, Pietro Pavlica 5 \\ ${ }^{1}$ UO di Radiologia, Ospedale S. Antonio, Tolmezzo, Udine, Italy; \\ ${ }^{2}$ Dipartimento di Radiologia, Università di Trieste, Trieste, Italy; \\ ${ }^{3}$ UO di Urologia I Universitaria, Università di Bari, Italy; \\ ${ }^{4}$ UO di Radiologia, Ospedale Maggiore, Bologna, Italy; \\ ${ }^{5}$ GVM Care and Research, Villalba Hospital, Bologna, Italy.
}

\begin{abstract}
Summary The increased use of ultrasound in patients with urological and andrological symptoms has given an higher detection of intra-testicular nodules. Most of these lesions are hypoechoic and their interpretation is often equivocal.

Recently, new ultrasound techniques have been developed alongside of B-mode and color-Doppler ultrasound. Although not completely standardized, contrast-enhanced ultrasound (CEUS) and tissue elastography (TE), added to traditional ultrasonography, can provide useful information about the correct interpretation of incidentally detected non-palpable testicular nodules.

The purpose of this review article is to illustrate these new techniques in the patient management.
\end{abstract}

KEY wORDs: Testicular lesions; Ultrasound; Contrast enhanced ultrasound; Elastography.

Submitted 3 October 2014; Accepted 31 October 2014

\section{INTRODUCTION}

The increased use of ultrasound (US) in patients with urological and andrological symptoms has given an higher detection of intra-testicular nodules. Most of these lesions are hypoechoic and their interpretation is often equivocal (1). The incidence of non-palpable testicular lesions depends on their size. Non-palpable nodules with a diameter of $10 \mathrm{~mm}$ account for about $0.2-1 \%$ of the patients with testicular nodules investigated with US (2-5). Most of these nodules are benign, including Leydig cell tumor as the main lesion. Nevertheless, if US is inconclusive, surgical exploration is the treatment of choice due to possible malignant nature of the nodule (6).

By overcoming the limitation of B-mode and colorDoppler ultrasound, new techniques such as contrastenhanced ultrasound (CEUS) and tissue elastography (TE) were explored for characterizing the testicular nodules in order to select the appropriate treatment.

\section{CONTRAST-ENHANCED ULTRASOUND}

Over the past decade, US contrast agents have gained a significant role in the characterization of focal lesions in liver, pancreas, spleen and kidneys. Their use in the testis is not well establish, even if some Authors advocated their utility in trauma, infarction, and tumors.

US contrast agents are gas-filled microbubbles of small size (less than $10 \mu \mathrm{m}$ ) able to diffuse in the blood allowing the visualization of the vascularization of the nodules. They are administered intravenously at the dose of $4.8 \mathrm{~mL}$ (one vial of contrast agent) followed by $10 \mathrm{~mL}$ of saline solution by an antecubital vein. After a mean delay of 20 seconds, the contrast agent reaches the testes giving its vascular map. The nodules can be depicted as hyper-enhancing, hypo-enhancing or non-enhancing masses in comparison with surrounding tissue. Some Authors advocated use of CEUS in the preoperative assessment of testicular lesions with hypervascularity as an important feature in the diagnosis of malignancy (7). Bubbles remain visible for 2-3 minutes after injection, therefore contrast intensity gradually decreases.

\section{TISSUE ELASTOGRAPHY}

Tissue elastography (TE) has been recently introduced for making non-invasive measurements of the mechanical properties of tissue. It is an imaging method of assessment for the elasticity of biological tissues (8). It represents a "new way" of palpation, where a portion of tissue is compressed and the degree to which it displaces is assessed. The most common way to displace the tissue is a manual application of a slight longitudinal compression with a conventional probe (so called "strain imaging"): the different tissues create different responses according to their specific elastic modulus (9). TE evaluates the relative elasticity of different tissues in a selected region of interest by using a fast cross correlation technique and a combined autocorrelation method. It creates an elastogram that is superimposed to the B-mode ultrasound image of the tissue and updated in real-time.

By convention, the elastograms display a colour-coded map of the relative elasticity. The normal testis in color scale elasticity imaging shows homogenous, soft stiffness. Focal lesions depicted as hard on elastography are suspicious for malignancy. Some authors found $87.5 \%$

No conflict of interest declared. 
sensitivity, 98.2\% specificity, 93.3\% PPV, 96.4\% NPV and $95.8 \%$ accuracy in differentiating malignant from benign lesions in 144 nodules/pseudo-nodules using TE (8). They concluded that TE was a very useful technique in assessing small testicular nodules and all types of pseusonodules and could be helpful in deciding the most appropriate clinical approach, allowing in particular conservative management in selected cases.

\section{TESTICULAR ADRENAL RESTS}

Testicular adrenal rests are benign corticotropin-dependent lesions that are often asymptomatic and occur frequently in male patients with congenital adrenal hyperplasia $(\mathrm{CAH})$ but have also been described in patients with Cushing's syndrome and Addison's disease (10). The reported prevalence by sonography however varies between $24 \%$ and $94 \%$. Histologically, testicular adrenal rests consist of hyperplastic adrenal cortical tissue originating from aberrant adrenal tissue that descends with the gonads during embryonic migration (11). On sonography, the testicular adrenal rests mostly appear hypoechoic although they may be heterogeneous or hypere-

Figure 1 Adrenal rest.

a) B-mode US shows a hypoechoic nodule with calcifications.

b) On color Doppler the nodule appear hypovascular.

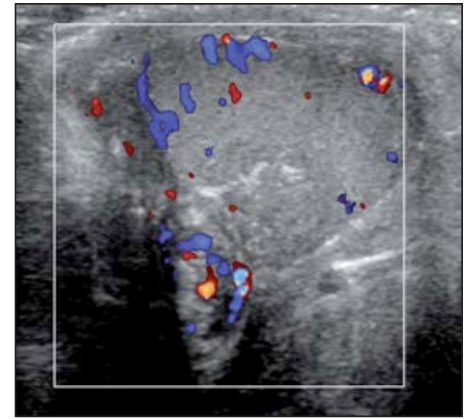

c) At CEUS the nodule shows to be hyperenhancing in the arterial phase.

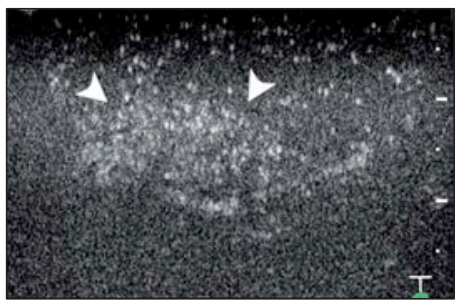

d) On TE the nodule is soft, similar to the surrounding testis.

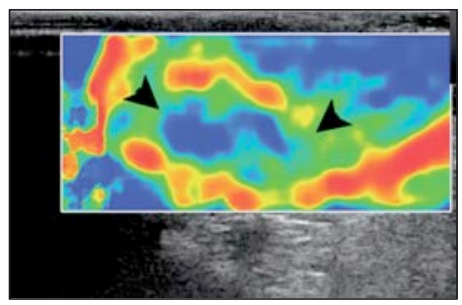

choic. Calcifications may be present. The adrenal rests are usually bilateral. An important finding in adrenal rests is that vessels coursing through the lesion are not deviated and this is considered an important feature. CEUS shows the nodules to be hyperenhancing in arterial phase with isoenhancement in the venous and later phase. On TE the nodules are usually soft, similar to the surrounding testis (Figure 1).

\section{SEGMENTAL TESTICULAR INFARCTION}

Segmental testicular infarction is an uncommon clinical situation. Etiology is largely considered idiopathic, but cases have been described occurring in patients with hyper-coagulability disorders, vasculitides, or following torsion, trauma, infection (12), and iatrogenic vascular injury (13-15). According with Bilagi et al. (1), segmental testicular infarction typically presents as a solitary solid wedge shaped or round area in the testis, hypoechoic or with mixed echogenicity, with markedly dimin-

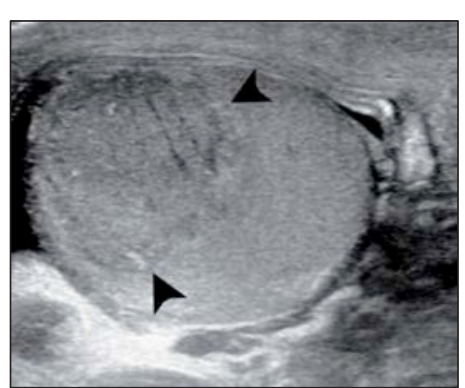

Figure 2.

Segmental testicular infarction.

a) B-mode US shows a hypoechoic nodule with mixed echogenicity.

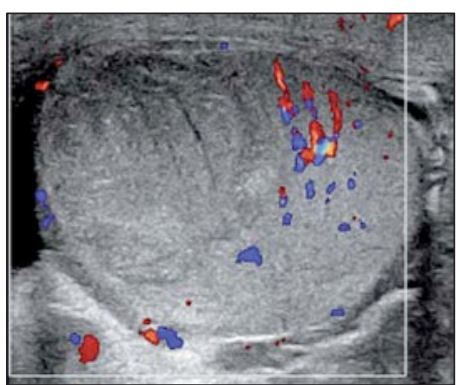

b) On color Doppler the vascularity is absent.

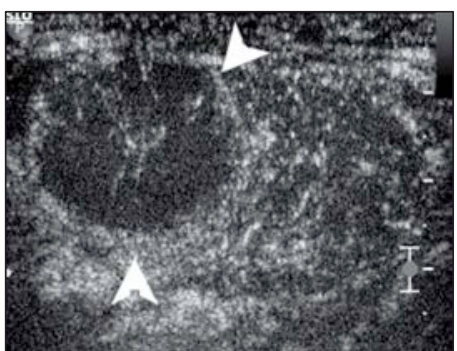

c) CEUS shows a characteristic with a perilesional rim of enhancement.

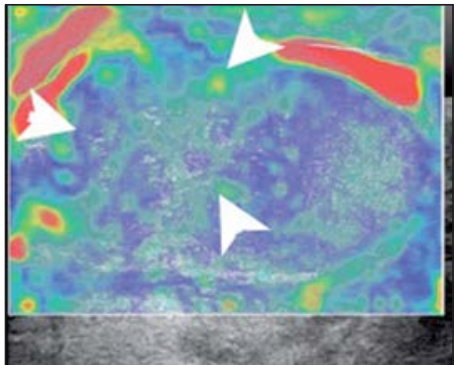

d) On TE consistency is slightly soft. 
ished or absent vascularity. Differential diagnosis with a tumor less vascularised than surrounding testicular parenchyma may be problematic in rounded lesions and when vascularity is not completely absent at color Doppler interrogation. CEUS improve characterization showing a non-enhancing lesion formed by ischemic parenchymal lobules. It therefore provided additional information that may be useful to differentiate this nonsurgical lesion from hypovascular tumors also in cases with equivocal features at color Doppler interrogation by presence of intralesional color spots. As the nodule is composed of necrotic tissue, on TE segmental testicular infarction is usually soft, although in acute cases consistency may be slightly increased due to edema (Figure 2).

\section{LEYDIG CELL TUMOR}

Leydig cell tumor is a relatively uncommon condition that is characterized by focal proliferation of the androgen-synthesizing interstitial cells of Leydig (16). Histologically, it is characterized by an increased number of testicular Leydig cells which displace and compress the seminiferous tubules. Leydig cell tumor constitute about $1-3 \%$ of all testicular tumors, and it affects males of 22 to 61 years with a mean age of 37 years (17). On B-mode US, Leydig cell tumor commonly appears as an hypoechoic nodule within the testicular parenchyma. The vascularity within the nodules is variable but usual-

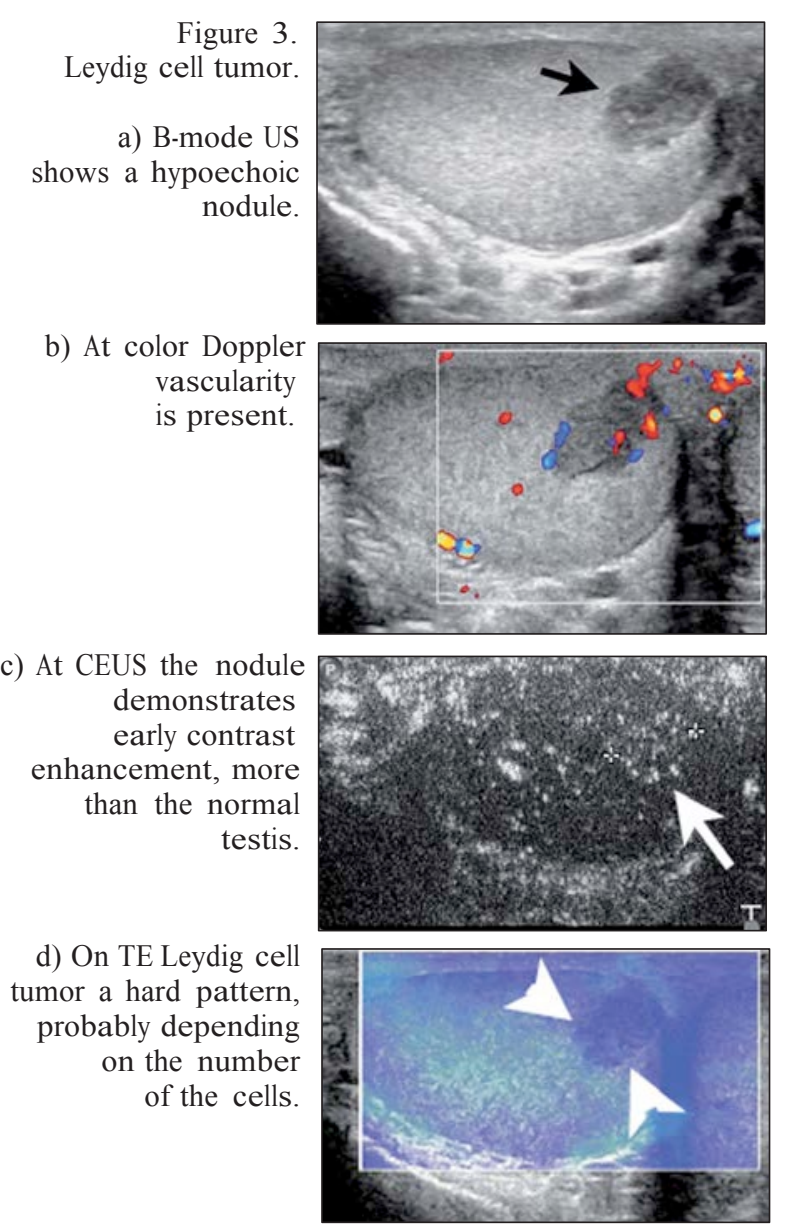

ly increased. The nodule usually demonstrates early contrast enhancement at CEUS, more than the normal testis. Wash-out is often rapid.

On TE Leydig cell tumor can demonstrate a soft or a hard pattern, depending on the number and in the size of the Leydig cells, lymphatic or vascular invasion, cytonuclear atypia, number of mitoses, absence of well-defined edge or a capsule (Figure 3 ).

\section{SEMINOMA}

Classic seminomas histologically are usually homogeneously solid, lobulated masses that may contain sharply circumscribed areas of necrosis. Microscopically, tumor cells are uniform with abundant clear cytoplasm characteristically arranged in nests outlined by fibrous bands; in $80 \%$ of cases, these bands are infiltrated by lymphocytes and plasma cells, possibly due to a host reaction to the tumor (18). The imaging features of seminomas reflect their histologic characteristics and their uniform cellular nature. On US, seminoma is a homogeneously

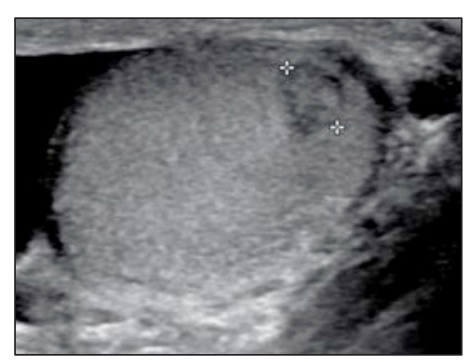

Figure 4.

Seminoma.

a) B-mode US shows a hypoechoic rounded lesion.

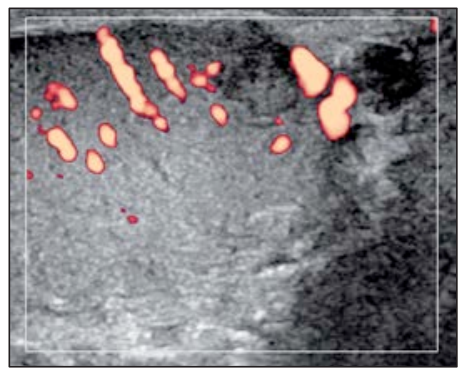

b) At color Doppler the lesion appears hypovascular.

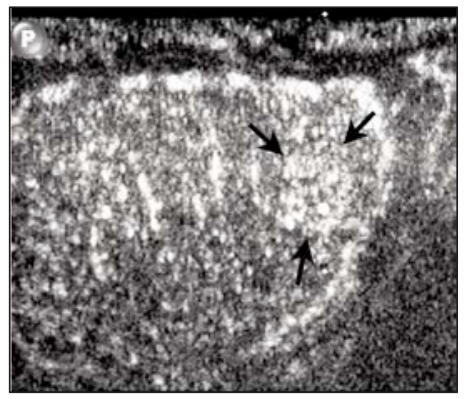

c) CEUS shows a rapid enhancement of the lesion.

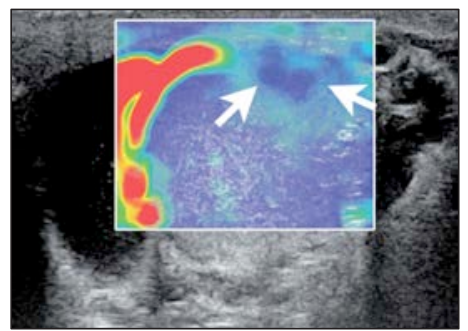

d) On TE the nodule is hard. 
hypoechoic rounded lesion; it may be lobulated or multinodular appearance. Cystic-like spaces are uncommon. Seminoma is usually hypervascular at color Doppler interrogation. CEUS shows a rapid enhancement of the lesion with an abnormal depiction of crossing vessel within the nodule. There is a rapid wash-out but a persistence of the crossing vessels sign. On TE the nodule is usually hard, on occasion, with soft intralesional areas due to necrotic changes (Figure 4).

\section{NONSEMINOMATOUS GERM CELL TUMORS}

This is a large group of histologically heterogeneous neoplasms. Four basic types can be recognized: embryonal carcinoma, teratoma, choriocarcinoma, and yolk sac tumor. The combination of two or more types of these neoplasms results in mixed GCTs. Embryonal carcinoma has a more variable appearance than seminoma. It is mainly a solid tumor containing foci of hemorrhage and necrosis. Teratoma is predominantly cystic and multiloculated. All types of tissues can be seen within the tumor, most commonly fat, cartilage and various types of epithelium. These tumors are further divided into mature and immature teratomas and those with malignant areas. Choriocarcinoma represents the most lethal form of testicular carcinomas. This tumor is often small, usually hemorrhagic, and partially necrotic. Yolk sac tumor has a soft consistency and a microcystic appear-

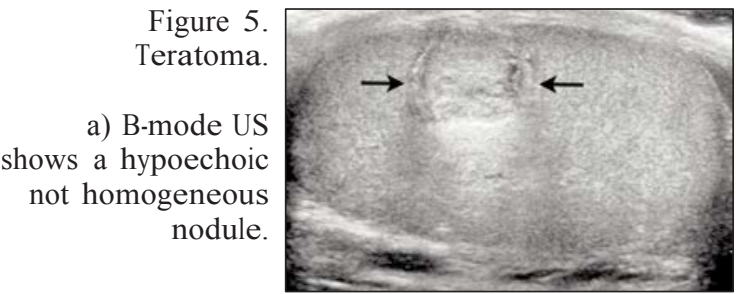

b) At color Doppler vascularity is poor.

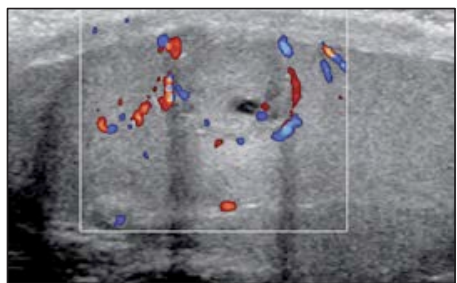

c) CEUS demonstrates some bubbles within the nodule suggesting the malignancy.

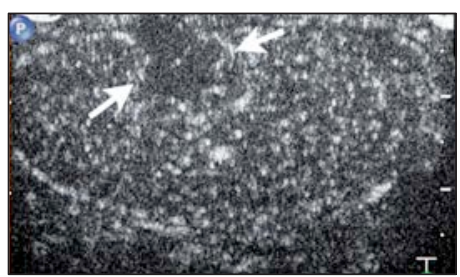

d) On TE the nodule appears clearly hard

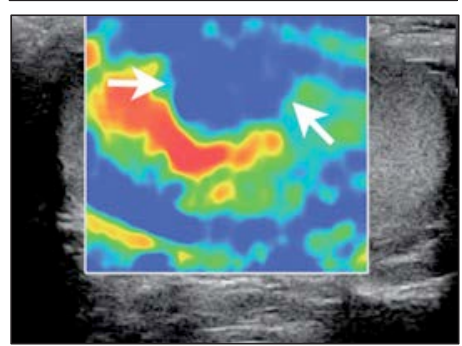

ance. Therefore, nonseminomatous testicular tumors are expected to appear as hypoechoic not homogeneous masses on US, with anechoic areas of necrosis and hyperechoic areas of calcification. Increased vascularity may or may not be demonstrated. However, CEUS is more able to demonstrate the vascularity of the nodule, sometimes with rare microbubbles within the lesion suggesting the malignancy. On TE these nodules appear clearly hard (Figure 5).

\section{CONCLUSION}

US is the imaging modality of choice for scrotal pathologies. Opposite to palpable testicular masses, non-palpable incidental testicular nodules are often benign and an accurate diagnosis is relevant for the appropriate treatment. Advanced and innovative US technology allows a better characterization of small testicular nodules. CEUS and TE are a useful adjunct to traditional B-mode and colorDoppler examination, clearly identifying vascularization and consistency of the nodule.

Although no ultrasound appearances may be entirely diagnostic, a combined evaluation of the grey-scale, vascular, and elastographic features of the nodule may allow a better confidence in the final diagnosis guiding the urologist to the appropriate treatment.

\section{REFERENCES}

1. Carmignani L, Gadda F, Gazzano G, et al. High incidence of benign testicular neoplasms diagnosed by ultrasound. J Urol. 2003; 170:1783-6.

2. Avci A, Erol B, Eken C, Ozgok Y. Nine cases of nonpalpable testicular mass: an incidental finding in a large scale ultrasonography survey. Int J Urol. 2008; 15:833-6.

3. Connolly SS, D'Arcy FT, Gough N, et al. Carefully selected intratesticular lesions can be safely managed with serial ultrasonography. BJU Int. 2006; 98:1005-7.

4. Müller T, Gozzi C, Akkad T, et al. Management of incidental impalpable intratesticular masses of $<$ or $=5 \mathrm{~mm}$ in diameter. BJU Int. 2006; 98:1001-4

5. Toren PJ, Roberts M, Lecker I, et al. Small incidentally discovered testicular masses in infertile men-is active surveillance the new standard of care? J Urol. 2010; 183:1373-7

6. Albers P, Albrecht W, Algaba F, et al. European Association of Urology. EAU guidelines on testicular cancer: 2011 update. Eur Urol. 2011;60:304-19.

7. Lock G, Schmidt C, Helmich F, et al. Early experience with contrast-enhanced ultrasound in the diagnosis of testicular masses: a feasibility study. Urology. 2011;77:1049-53.

8. Goddi A, Sacchi A, Magistretti G, et al. Real-time tissue elastography for testicular lesion assessment. Eur Radiol. 2012; 22:721-30.

9. Aigner F1, De Zordo T, Pallwein-Prettner L, et al. Real-time sonoelastography for the evaluation of testicular lesions. Radiology. 2012;263:584-9.

10. Dogra V, Nathan J, Bhatt S. Sonographic appearance of testicular adrenal rest tissue in congenital adrenal hyperplasia J Ultrasound Med. 2004;23:979-81.

11. Stikkelbroeck NM, Suliman HM, Otten BJ, et al. Testicular adrenal 
rest tumours in postpubertal males with congenital adrenal hyperplasia: sonographic and MR features. Eur Radiol. 2003; 13:1597-603.

12. Bilagi P, Sriprasad S, Clarke JL, et al. Clinical and ultrasound features of segmental testicular infarction: six-year experience from a single centre. Eur Radiol. 2007; 17:2810-8.

13. Magill P, Jacob T, Lennon GM. A rare case of segmental testicular infarction. Urology. 2007; 69:983 e987-8.

14. Mincheff T, Bannister B, Zubel P. Focal testicular infarction from laparoscopic inguinal hernia repair. JSLS. 2002; 6:211-3.

15. Secil M, Kocyigit A, Aslan G, et al. Segmental testicular infarc- tion as a complication of varicocelectomy: sonographic findings. J Clin Ultrasound. 2006; 34:143-5.

16. Mati W, Lam G, Dahl C, et al. Leydig cell tumour--a rare testicular tumour. Int Urol Nephrol. 2002;33:103-5.

17. Carmignani L1, Salvioni R, Gadda F, et al. Long-term followup and clinical characteristics of testicular Leydig cell tumor: experience with 24 cases. J Urol. 2006; 176:2040-3.

18. Ulbright TM Germ cell tumors of the gonads: a selective review emphasizing problems in differential diagnosis, newly appreciated, and controversial issues. Mod Pathol. 2005;18 Suppl 2:S61-79.

\section{Correspondence}

Massimo Valentino, MD

massimo.valentino@ass3.sanita.fvg.it

UO di Radiologia, Ospedale S. Antonio, 33028 Tolmezzo, Udine, Italy

Michele Bertolotto, MD

Dipartimento di Radiologia, Università di Trieste, Trieste, Italy

Pasquale Martino, MD

UO di Urologia I universitaria, Università di Bari, Italy

Libero Barozzi, MD

UO di Radiologia, Ospedale Maggiore, Bologna, Italy

Pietro Pavlica, MD

GVM Care and Research, Villalba Hospital, Bologna, Italy 